\title{
Creating an inclusive mall environment with the PRECEDE-PROCEED model: a living lab case study
}

Sara Ahmed, Bonnie Swaine, Marc Milot, Caroline Gaudet, Tiiu Poldma, Gillian Bartlett, Barbara Mazer, Guylaine Le Dorze, Skye Barbic, Ana Maria Rodriguez, Hélène Lefebvre, Philippe Archambault, Dahlia Kairy, Joyce Fung, Delphine Labbé, Anouk Lamontagne \& Eva Kehayia

To cite this article: Sara Ahmed, Bonnie Swaine, Marc Milot, Caroline Gaudet, Tiiu Poldma, Gillian Bartlett, Barbara Mazer, Guylaine Le Dorze, Skye Barbic, Ana Maria Rodriguez, Hélène Lefebvre, Philippe Archambault, Dahlia Kairy, Joyce Fung, Delphine Labbé, Anouk Lamontagne \& Eva Kehayia (2017) Creating an inclusive mall environment with the PRECEDEPROCEED model: a living lab case study, Disability and Rehabilitation, 39:21, 2198-2206, DOI: 10.1080/09638288.2016.1219401

To link to this article: https://doi.org/10.1080/09638288.2016.1219401

央 Published online: 23 Jan 2017.

Џll Article views: 643

View Crossmark data $־$
Submit your article to this journal $\widetilde{\pi}$

View related articles $\widetilde{\nearrow}$

Citing articles: 4 View citing articles 지 


\title{
Creating an inclusive mall environment with the PRECEDE-PROCEED model: a living lab case study
}

\author{
Sara Ahmed ${ }^{a, b, c}$ (D), Bonnie Swaine ${ }^{b, d, e}$, Marc Milot $^{a}$, Caroline Gaudet ${ }^{a, g}$, Tiiu Poldma ${ }^{b, h, m}$, Gillian Bartlett ${ }^{i}$ (D, \\ Barbara Mazer $^{a, b, f}$ (D), Guylaine Le Dorze $e^{b, e, j}$ (D), Skye Barbic ${ }^{k}$ (D), Ana Maria Rodriguez ${ }^{a}$ (D) Hélène Lefebvre ${ }^{b, e, l}$, \\ Philippe Archambault ${ }^{a, b, f}{ }^{a}$ Dahlia Kairy ${ }^{b, d, m}$, Joyce Fung ${ }^{a, b, f} \mathbb{D}$, Delphine Labbéb,e,n ${ }^{(D)}$, Anouk Lamontagne ${ }^{a, b, f^{\prime}}$ and \\ Eva Kehayia ${ }^{a, b, f}$
}

\begin{abstract}
${ }^{\mathrm{a} S}$ School of Physical and Occupational Therapy, McGill University, Montréal, Canada; ${ }^{\mathrm{b}}$ Centre de recherche interdisciplinaire en réadaptation du Montréal métropolitain (CRIR), Montréal, Canada; 'Centre de réadaptation Constance-Lethbridge du Centre intégré universitaire de santé et de services sociaux (CIUSSS) du Centre-Ouest-de-I'Île-de-Montréal, Montréal, Canada; 'École de réadaptation, Université de Montréal, Montreal, Canada; ${ }^{e}$ Centre de réadaptation Lucie-Bruneau du CIUSSS du Centre-Sud-de-l'Ille-de-Montréal, Montréal, Canada; fJewish Rehabilitation Hospital du Centre intégré de santé et de services sociaux (CISSS) de Laval, Laval, Canada; ${ }^{9}$ Bruyère Research Institute, Ottawa, Canada; hÉcole de design, Faculté de l'aménagement, Université de Montréal, Montréal, Canada; 'Department of Family Medicine, McGill University, Montréal, Canada; 'École d'orthophonie et d'audiologie, Université de Montréal, Montréal, Canada; ${ }^{k}$ Department of Occupational Science and Occupational Therapy, University of British Columbia, Canada; 'Faculté des sciences infirmières, Université de Montréal, Montréal, Canada; ${ }^{\mathrm{m} I n s t i t u t ~ d e}$ réadaptation Gingras-Lindsay-de-Montréal du CIUSSS du Centre-Sud-de-I'Île-de-Montréal, Montreal, Canada; ${ }^{n}$ Département de psychologie, Université du Québec à Montréal, Montréal, Canada
\end{abstract}

\section{ABSTRACT}

Purpose: Although public environments provide opportunities for participation and social inclusion, they are not always inclusive spaces and may not accommodate the wide diversity of people. The Rehabilitation Living Lab in the Mall is a unique, interdisciplinary, and multi-sectoral research project with an aim to transform a shopping complex in Montreal, Canada, into an inclusive environment optimizing the participation and social inclusion of all people.

Methods: The PRECEDE-PROCEDE Model (PPM), a community-oriented and participatory planning model, was applied as a framework. The PPM is comprised of nine steps divided between planning, implementation, and evaluation.

Results: The PPM is well suited as a framework for the development of an inclusive mall. Its ecological approach considers the environment, as well as the social and individual factors relating to mall users' needs and expectations. Transforming a mall to be more inclusive is a complex process involving many stakeholders. The PPM allows the synthesis of several sources of information, as well as the identification and prioritization of key issues to address. The PPM also helps to frame and drive the implementation and evaluate the components of the project.

Conclusion: This knowledge can help others interested in using the PPM to create similar enabling and inclusive environments world-wide.

\section{ARTICLE HISTORY}

Received 20 September 2015 Revised 16 July 2016 Accepted 28 July 2016

\section{KEYWORDS}

PRECEDE PROCEED; participation; inclusion; environment; enabling

\section{> IMPLICATION FOR REHABILITATION}

- While public environments provide opportunities for participation and social inclusion, they are not always inclusive spaces and may not accommodate the wide diversity of people.

- The PRECEDE PROCEDE Model (PPM) is well suited as a framework for the development, implementation, and evaluation of an inclusive mall.

- Environmental barriers can negatively impact the rehabilitation process by impeding the restoration and augmentation of function.

- Removing barriers to social participation and independent living by improving inclusivity in the mall and other environments positively impacts the lives of people with disabilities

\section{Introduction}

Participation in meaningful activities is essential to ensure physical, cognitive, and emotional well-being.[1] Approximately 3.8 million Canadians, representing $13.7 \%$ of the adult population, are, however, experiencing limitations in their daily activities due to a disability.[2] Individuals with disabilities have reduced community participation $[3,4]$ and older adults with poor physical and cognitive health are at greater risk of isolation.[5]
Community participation, such as the types of activities that take place in malls, positively impacts the health of individuals.[1] Malls are important hubs of human activity, promoting not only opportunities to acquire material goods, but to participate in meaningful social and leisure activities.[6] They provide sensory stimulation, safety, comfort, convenience, and social interactions.[7-9] According to social ecology theory, persistent behaviors and expectations are formed over time within particular public 
settings.[10] People interacting within an environment, such as a shopping mall, eventually learn patterns of behavior through socialization, contributing to the development of adaptive patterns of participation. Such interactions between persons with and without a disability are known to promote the appreciation of each other's "sameness" and thus work to reduce prejudice.[11]

Although malls provide opportunities for participation and social inclusion, they are not always designed to accommodate the diversity of its patrons. Their design is typically geared towards young and abled-bodied individuals. According to Lawton's Environmental Press Model, if the demands of the environment exceed the person's abilities, a person-environment misfit can be created, and loss of function can ensue.[12-14] For the elderly, this not only negatively affects function, but also their sense of identity and belonging.[15,16] Exclusion creates challenges not only for the elderly, but also for those with physical, mental, and emotional disabilities.[17-19] Exclusion ensues from the failure to take a universal and inclusive design approach into consideration, and can be prevented by gathering all necessary information regarding the needs of the population and understanding these needs from the design perspective at the outset.[20] An inclusive approach might be used earlier in the design process,[21] however, there are challenges to achieving this.

Removing environmental barriers can accelerate the rehabilitation process by enhancing function,[22] and in turn increasing individuals' participation, and quality of life. It is also important to consider the social and individual factors in the design of public spaces. Social obstacles include others' attitudes toward people with disabilities, or subtle forms of discrimination and bias, which negatively impacts interactions.[9,20] General attitudes towards people with disabilities can also be shaped by the manner in which individuals with disabilities interact in a public setting.[23] A mall designed to be inclusive might enable the realization of adaptive behaviors and this improved participation can lead to a more open and accepting attitude from the general public. As life expectancy continues to increase in Canada, so will the prevalence of functional impairments and disabilities.[24] Thus, the need for inclusive spaces to accommodate individuals with disabilities within the mall environment will only continue to grow.

With this in mind, in 2011, researcher members of the Center for Interdisciplinary Research in Rehabilitation of Greater Montreal (CRIR) in partnership with Cominar REIT, the owner and manager of Alexis Nihon mall, initiated the RehabMaLL project, entitled: "A Rehabilitation Living Lab: Creating Enabling Physical and Social Environments to Optimize Social Inclusion and Participation of People with Physical Disabilities" (funded by Fonds de recherche en santé du Québec grant). At the time, the Alexis Nihon shopping mall was about to undergo major renovations. The mall owners agreed to assist research by allowing the mall to become a "living lab", providing investigators with access to a naturalistic setting for research. A living lab approach involves a public-private-people partnership, enabling consumers/citizens (e.g., user communities) to take active roles as contributors and co-creators in the research, development and innovation process. The user community is also involved in the testing and development of products and services within the naturalistic environment in which they would be expected to use the innovation.[25,26]

One of the key strengths of the project is its strong interdisciplinary and multi-sectoral nature, bringing together different research groups across disciplines (e.g., biomedical, clinical, psychosocial, design) and stakeholder groups (e.g., merchants, community organizations, researchers, users/people with a disability).
These strengths, however, also present a challenge by increasing the complexity of the project.

Green and Kreuter's PRECEDE (Predisposing, Reinforcing, and Enabling Constructs in Educational/Environmental Diagnosis and Evaluation) -PROCEED (Policy, Regulatory, and Organizational Constructs in Educational and Environmental Development) Model (PPM) was used to guide the development, implementation, and evaluation aspects of the RehabMaLL.[27,28] While other ecological models can be used, the PPM is particularly well suited for the RehabMall project as it is a community oriented and participatory planning model that relies on the participation of the target population; the individuals who need to voluntarily engage in health-promoting behaviors. As such the PPM requires that the target population and stakeholders partake in every phase of model development, which makes it compatible with the participatory approach required for the development, implementation, and sustainability of the RehabMaLL Living Lab.[29] The model also focuses on the community as the wellspring of health promotion as health is influenced by community attitudes, shaped by community environment (physical, social, political, and economic), and community history. It focuses on the health of populations rather than on individuals, unlike intrapersonal theories of health behavior (Health Belief Model, Transtheoretical Model, and Theory of Planned Behavior).[29] The model can be used to iteratively integrate planning, , and evaluation stages, help set priorities and allocate resources, and provides a framework to guide network activities.[30] The desired outcomes are decided at the beginning of the planning phases permitting the establishment of metrics, important in evaluating the program.[28] The PPM has been used to develop interventions that have been empirically evaluated in a range of domains including physical activity promotion,[31] infectious disease prevention,[32] and health education.[33] The PPM could also be used to promote the transferability of the processes of the RehabMaLL project to similar research environments and national and international programs.

\section{Objectives}

The aim of this paper is to demonstrate how the PPM was applied as a framework for the development of an inclusive environment in the context of the RehabMaLL project conducted in an existing and renovation-ready public setting. We present the planning phases (1-5) of the PPM and their application to the development of an inclusive mall environment.

\section{Methods}

\section{The PRECEDE-PROCEED Model phases}

The PPM provides the blueprint for the construction and evaluation of programs/projects in nine steps divided between the planning components (phases 1-5), implementation (phase 6) and evaluation components (phases 7-9).[30] The planning components of the PPM (PRECEDE) include phases (1) a social needs assessment to identify the needs of the target community and the desired outcome, (2) an epidemiological assessment to identify the characteristics of the community in relation to the identified problems, (3) a behavioral and environmental assessment to identify the specific issues hindering participation and reducing inclusivity at the mall, (4) an educational and organizational diagnosis to inform the development of the program interventions, and (5) an administrative and policy assessment and intervention alignment to analyze the policies, resources and organizational situations that could hinder or facilitate development and implementation of 
interventions. The implementation and evaluation components (PROCEDE) include phases, (6) implementation, which involves the implementation of interventions or other program components at the mall, (7) a process evaluation to evaluate the implementation activities, (8) an impact evaluation to determine the immediate impacts of the interventions at the mall, and (9) an outcome evaluation to determine whether the ultimate goals of the RehabMaLL project were reached. The PPM assisted in the synthesis and assessment of data/information being collected, and enabled measurement of the performance of the overall project (or group of research activities) through ongoing monitoring and reporting of outcomes.

\section{Mall setting}

The setting was the Alexis Nihon shopping center located west of downtown Montreal. It is a multipurpose complex comprised of over 100 stores, office towers, and a residential tower. The mall covers 400,000 square feet of commercial rental space across three floors, and is directly accessible by subway, car, bus, and by a bicycle path. However, the subway is not accessible for persons with mobility impairments. It is situated near a large College as well as a hospital. It draws $\sim 38,000$ people daily.

\section{Governance, stakeholder input, and support}

The PPM guided the RehabMaLL project governance and committee members at all major steps, including planning, implementation, and evaluation of research projects. Multiple meetings, workshops, and discussions were held, during which stakeholders (researchers, project partners, and clinicians) were able to provide information and feedback. General network meetings were held every year where the various stakeholders within the RehabMaLL project met to discuss progress and plan the next steps, and a number of executive meetings informed the application of the PPM. The governance of the RehabMaLL project and active stakeholders input reflected the emphasis of the PPM in assessing social needs independently and from the perspective of the community.

The overall RehabMaLL project was governed by two team leaders who were supported by nine core team/executive committee members whose mandate included overseeing research and knowledge translation activities, as well as determining budgets and research priorities, with decisions reached by consensus. The core team was made up of eight professors from three major Montreal universities and a project manager. An advisory board comprised of six individuals with expertise in the areas of community-based participatory research, social participation and inclusion, communication and language, measurement, quality of life, and epidemiology, ensured the project maintained alignment with objectives and offered guidance and solutions to issues and challenges. The Statistical and Evaluation and the Community of Practice (rehabilitation clinicians, researchers, persons with disabilities, mall users and non-users) groups were responsible for a number of evaluation and implementation-related activities, respectively. The Statistical and Evaluation group, in collaboration with other stakeholders, and project governance/groups, were also responsible for leading the application of the PPM to the RehabMaLL project. In addition to the primary partnership with Cominar REIT, the owner and manager of Alexis Nihon mall, other partners and collaborators included private industry (Institut National d'Optique, Motek), community organizations (Altergo, Théâtre Aphasique, Cummings Center) as well as 50 local, national, and international researchers who contributed their time, knowledge, and resources to the project

\section{Research projects and other data sources informing the PPM}

The RehabMaLL activities were informed by a series of sub-projects that provided data on the phases of the PPM. Open calls for funding were regularly conducted for research addressing priorities of the project and to inform the PPM. These sub-projects generated observations and outcomes that were reported back to the main over-arching RehabMaLL project and to stakeholders, including the architects and designers during the renovation process. Not all research projects were necessarily conducted on-site at Alexis Nihon, but all were framed to contribute to meeting the overall objective of improving inclusivity at the mall.

The sub-projects were comprised of various types of study designs and methodologies. Projects funded by the RehabMaLL project were asked to use a participatory approach [34] to include members representing one or more of the stakeholder groups including patients, clinicians, government, and regional decision makers, as well as mall owners or mall representatives. While many publications resulted from the RehabMaLL project research activities, we do not report or discuss in detail the findings from individual studies, but rather focus on discussing the overall process of applying the PPM to the project activities and the overall synthesis of the information gathered. The RehabMaLL project and the PPM were also informed by additional sources of data including literature reviews, local policy documents, and content emerging from key informant interviews, and consultation meetings.

\section{Application of the precede-proceed model to the RehabMaLL project}

\section{Planning phases}

Here, we present the planning phases (1-5) of the PPM and their application to the development of an inclusive mall environment. These phases provided an initial assessment of the needs of the mall user community, and informed the development of program interventions by providing a comprehensive understanding of the mall environment, the participants and how they interact within the mall.

\section{Phases 1 and 2: Social and epidemiological assessment}

A number of sub-projects conducted at Alexis Nihon contributed to the social and epidemiological assessment phases. They helped confirm the lack of inclusivity at Alexis Nihon and its impact on mall patrons with various disabilities. The social assessment focused on identifying the needs of the mall patrons, the social problems impacting their quality of life, and their desired outcomes. The epidemiological assessment phase involved identifying the characteristics of the target community at the mall. The types of functions impacted in individuals with disabilities at the mall, as well as impairment in activity and participation were mapped according to the International Classification of Functioning, Disability, and Health (ICF) framework.[35,36]

In order to gather baseline data on the characteristics of the mall patrons, a series of observations including "people counts" were conducted at the mall, at various time frames, between 23 January and 29 January 2012. The observations were carried out in various critical zones within the mall (i.e., stairways, escalator, entrance). The baseline observations revealed that between $4 \%$ and $8 \%$ mall patrons had reduced mobility of caused by an 
impairment or due to particular situations or environmental obstacles (i.e., shopping with a stroller, employee pushing a cart). Of those with reduced mobility, $24.4 . \%$ were elderly, $15.8 \%$ were children including babies, $10.0 \%$ were able-bodied attendants, $0.5 \%$ were pregnant women, and $46.9 \%$ were classified as "other".

The sub-projects focused on individuals of all ages with impairments related to a number of diseases and conditions (ex: CNS lesions, spinal cord injuries, Parkinson's, chronic pain, visual, and hearing, speech/communication problems such as aphasia, developmental disorders) and included individuals requiring the use of wheelchairs and other mobility assistive devices. The functions impacted in individuals with disabilities identified by the research projects and initial assessment phases of the PPM included: (1) cognitive functions: intellectual, attentional, mnemonic, psychomotor, emotional, perceptual, higher level, language, calculation, sequencing complex movements, experience of self and time, (2) sensory functions: seeing and hearing, (3) voice and speech functions: voice, articulation, fluency and rhythm of speech, and alternative vocalizations, (4) neuromusculoskeletal and movement related functions: mobility of joints and bones, muscle strength and power, muscle tone, muscle endurance, motor reflex, control of voluntary movement, gait patterns, and sensations related to movement functions.

The population studied at the mall also included individuals without impairments in body function or activity and participation. For example, some sub-projects identified the needs of the family members and caregivers of persons with disability, as well as the health professionals working with the person. Also, included in the sub-projects were the residents of the residential towers, mall tenants and employees, members of community organizations, and vagrants. The reasons for visiting the mall were varied and included the acquisition of goods and services, socializing, safety, recreation, and leisure, physical activity, employment or volunteering, rehabilitation, dining, and passing through.

A number of inclusivity issues in activity and participation were identified, and fell under seven main areas. The areas included: (1) learning and application of knowledge (i.e., learning how to find particular stores or locations within the mall), (2) performance of general tasks: (i.e., the ability to use the washrooms or payment systems, (3) communication: (i.e., the ability to communicate with mall employees and other mall patrons), (4) mobility: (i.e., the ability to move independently and/or free of barriers within the mall and to access all locations), (5) the acquisition of goods and services: (i.e., the ability to purchase goods from stores and food items at the cafeteria), (6) interpersonal interactions and relationships: (i.e., the ability to meet friends and family members at the mall for socializing), and (7) community recreation and leisure: for example, the ability to participate in and to feel part of the mall community.

These findings helped understand the quality of life, health status, and needs of individuals with disabilities in regards to the mall environment and degree of inclusivity. They also determined and confirmed the overall social problems faced by people with disabilities resulting from issues with inclusivity at Alexis Nihon mall, and helped identify the improvements required for greater inclusivity and participation. Although certain populations may not have been included in the research projects conducted as part of the initial phases of the PPM, the impairments and functions identified are universal across disabilities and it is likely that people with other types of disabilities would have similar social and epidemiological determinants as those identified.[37]
Phase 3: Behavioral and environmental assessment

Phase 3 of the PPM identified the behavioral and environmental issues associated with a lack of inclusivity at the mall; issues hindering the participation of the individuals with disabilities in the mall environment.

This phase was informed by numerous projects exploring obstacles and facilitators in the social and physical environment.[38] For example, some research projects conducted at Alexis Nihon described the physical space characteristics, floor plans, and metrics charts to identify obstacles to navigation,[38] while other research projects included focus groups with mall users with and without disabilities to synthesize information on the experiences and expectations in relation to inclusivity measures. The projects examined a wide range of issues impacting inclusivity at the mall, such as issues with the construction, accessibility, or with broader social factors. The synthesis of information was facilitated by holding working groups where researchers, community members, and other stakeholder groups helped prioritize the issues identified by the data collection and research projects.

Table 1 summarizes the inclusivity and accessibility issues at Alexis Nihon, informed in part by a number of RehabMaLL research projects.[9,20,38-47]

\section{Phase 4: Educational and organizational diagnosis}

Phase 4 involved the identification of the factors that should be targeted to address the behavioral and environmental issues at the shopping mall. This phase informs the development of the program interventions by determining the predisposing, enabling, and reinforcing factors. Predisposing factors are the antecedents that provide motivation for action. They include the knowledge, attitudes, beliefs, values, and confidence of stakeholders (mall owners and mall patrons). Enabling factors are the internal factors that enable stakeholders to act on their predispositions and include the availability of material and financial resources, as well as the mall personnel. Reinforcing factors provide the external rewards or incentives for the continuation of behaviors of the person at the mall. They include feedback and influences from health professionals, local laws and policies, media and more.

The predisposing, enabling, and reinforcing factors were determined for each of the issues identified in phase 3 . Issues that were amenable to change by interventions and environmental modifications were identified and prioritized. Table 2 provides predisposing, enabling, and reinforcing factors of the RehabMaLL project for a number of issues; some factors contributed to more than one of the identified inclusivity issues.

The most common predisposing, enabling, and reinforcing factors were knowledge, awareness, and perceptions of stakeholders at the mall, as well as communication/feedback mechanisms and information access. A cost-benefit comparison was conducted in order to prioritize issues based on their degree of feasibility/ changeability. For example, signage improvements were considered as low cost environmental modifications with a high degree of feasibility, and were expected to have a significant impact on the inclusivity of patrons with vision impairments. On the other hand, changes at the policy level changes, such as implementing mandatory training of employees, was less feasible and was associated with higher costs.

Phase 5: Administrative and policy assessment and intervention alignment

Phase 5 involved determining whether the interventions or modifications proposed were feasible with available resources, and 
Table 1. Summary of inclusivity issues impacting function and participation at the mall identified by the behavioral and environmental assessment.

\begin{tabular}{|c|c|c|}
\hline Area & Area definition & Examples of issues \\
\hline Outside the mall & $\begin{array}{l}\text { Outside the interior mall space (including both } \\
\text { mall and public physical spaces). }\end{array}$ & $\begin{array}{l}\text { - Poor accessibility for wheelchair-bound individuals, or others with } \\
\text { mobility assistive devices } \\
\text { - Via the subway (no elevator or ramp) } \\
\text { - No vehicle drop off area } \\
\text { - Poor signage outside the building }\end{array}$ \\
\hline Inside the mall & Interior physical space of the mall. & $\begin{array}{l}\text { - Poor signage inside the mall (e.g., location of elevator) } \\
\text { - } \quad \text { High noise level } \\
\text { - Inconsistent signage }\end{array}$ \\
\hline Social support & $\begin{array}{l}\text { Care of people with disabilities by other people } \\
\text { at the mall that impact perceived and actual } \\
\text { sense of belonging. }\end{array}$ & $\begin{array}{l}\text { - No system for shopper assistance } \\
\text { - Limited disability awareness training provided to employees } \\
\text { - Limited number of employees with disabilities }\end{array}$ \\
\hline Educational & $\begin{array}{l}\text { Knowledge and awareness of people at the mall } \\
\text { about disabilities and individual with } \\
\text { disabilities. }\end{array}$ & $\begin{array}{l}\text { - Limited public sensitization and awareness of people with disabilities } \\
\text { - } \quad \text { Lack of educational venues regarding needs of people with disabilities } \\
\text { - Lack of continuity of knowledge (staff turnover and part-timers) }\end{array}$ \\
\hline Psychosocial & $\begin{array}{l}\text { Support and resources at the mall that impact } \\
\text { psychological and subjective well-being. }\end{array}$ & $\begin{array}{l}\text { - Lack of peer support groups and events } \\
\text { - Lack of staff awareness to the presence of psychological signs of dis- } \\
\text { tress or how to manage inappropriate social behaviors } \\
\text { - Lack of consideration for the subjective experiences of people with } \\
\text { disabilities }\end{array}$ \\
\hline Communication & $\begin{array}{l}\text { Accessibility and communication/transfer of } \\
\text { information pertinent to experiences with the } \\
\text { mall (both on- and off-site). }\end{array}$ & $\begin{array}{l}\text { - Accessibility of information about the mall on the web not addressed } \\
\text { - No tools/processes for nonverbal communication } \\
\text { - No direct phone line to taxi company with disability-adapted vehicles }\end{array}$ \\
\hline Vision and hearing & Vision and audition at the mall. & $\begin{array}{l}\text { - Gaps in services adapted for color blindness } \\
\text { - No visible contrasts in signage } \\
\text { - No available auditory information for the visually impaired }\end{array}$ \\
\hline Mobility & $\begin{array}{l}\text { Ability to move freely and easily within the } \\
\text { mall. }\end{array}$ & $\begin{array}{l}\text { - Lack of rest spaces } \\
\text { - Lack of navigating space inside certain stores } \\
\text { - Lack of different sitting options }\end{array}$ \\
\hline Attitudinal & $\begin{array}{l}\text { Attitudes of people at the mall, including } \\
\text { patrons, shop owners, employees, and indi- } \\
\text { viduals with disabilities. }\end{array}$ & $\begin{array}{l}\text { - Negative attitudes and prejudices towards people with disabilities } \\
\text { - No tools to change attitudes and reduce marginalization, and to } \\
\text { address poor perceptions of competence experienced by many people } \\
\text { with disabilities }\end{array}$ \\
\hline Financial & Financial transactions at the mall. & $\begin{array}{l}\text { - Availability of work for people with disabilities } \\
\text { - Financial difficulties for people with disabilities limiting participation } \\
\text { - Payment systems difficult to use for certain people with disabilities }\end{array}$ \\
\hline Policy level & $\begin{array}{l}\text { Set of basic principles and associated guidelines } \\
\text { enforced by mall ownership and } \\
\text { management. }\end{array}$ & $\begin{array}{l}\text { - Lack of policy for mandatory employee awareness training } \\
\text { - Lack of incentives for shop owners to facilitate inclusion } \\
\text { - } \quad \text { No best practices for mall activities for individuals with disabilities }\end{array}$ \\
\hline
\end{tabular}

Table 2. Predisposing, enabling, and reinforcing factors for a number of issues.

Issue/determinant of function

and participation Predisposing factors

1. Poor interior signage

2. No shopper assistant system to provide information, assistance or direction for people with disabilities

Lack of knowledge by mall owner about signage and/or its impact on degree of inclusion for people with vision impairments/low vision

Lack of awareness by mall owner and shop owners of potential benefits of such assistance system and impact of not having one

3. Mall employee attitudes towards people with disabilities

Lack of awareness by mall and shop owners about attitude issues and/ or impact of attitude on inclusion and experience at mall/shops

4. Lack of rest spaces

Lack of awareness about the need for rest spaces and the impact on not providing such spaces
Enabling factors

Maintenance personnel not trained to identify poor signage or to develop optimal signage/ wayfinding

No feedback to management about potential need for such a system

Store employees not educated or trained to interact with people with disabilities

No feedback to management about potential need and benefits of such a system
Reinforcing factors

No public feedback to management/ maintenance personnel about impact of poor signage; lack of knowledge on how to implement better signage

General acceptance of lack of such system by the public; lack of knowledge on how to develop and implement a shopper assistance system; cost-barriers to develop

Little social awareness in general about the different needs and expectations of people with disabilities with regards to attitudes and treatment; lack of knowledge on how to change attitudes; costbarriers to implement changes.

General acceptance of lack of such rest spaces by the public; lack of knowledge or lack of initiative to develop rest spaces; cost-barriers to implement 
compatible with mall administrative policies. If they were not compatible, changes in mall administrative policies were explored if a particular potentially beneficial intervention required it.

Potential interventions/solutions were identified for each of the issues prioritized in phase 4 . In some cases, the research subprojects themselves informed the development and testing of novel interventions. For example, one project explored the impact of a training program regarding welcoming people with various functional limitation, on employees' knowledge and perceived self-efficacy. The findings from this project served to inform the development of further interventions targeting attitudinal and social issues.

As Alexis Nihon is privately owned, the activities within this phase were conducted by the project leaders/researchers in collaboration with mall administrators, leveraging the information collected and synthesized from all previous phases of the PPM. For example, to remediate poor interior signage and improve navigation, the addition of a number of signs and floor identifiers were planned to be added in key locations. Prior to doing so, an analysis of the policies, resources and circumstances at the mall that could hinder or facilitate the development and implementation of each of the interventions or modifications to the mall setting was undertaken.

\section{Implementation phase}

Phase 6: Implementation of program components and activities This phase is the first phase of the "PROCEED" component of the PPM, which focuses on the implementation of the selected interventions in-vivo. It entails the selection of intervention implementation methods and strategies, as well as identification of resources and required policy changes.

The RehabMaLL project implementation activities were dependent on continuous collaboration with the mall owners. The mall management and research team met frequently to provide updates, and to discuss strategic ways to integrate research findings into renovation plans. The RehabMaLL interventions have been implemented gradually over the years. Some projects are still in progress requiring constant maintenance and effort. Table 3 describes the interventions implemented to date and those that are still underway. Although interventions have focused primarily on physical changes at the mall, due to their higher degree of changeability and feasibility, we expect a greater breadth of interventions to be implemented, that will target other identified issues (e.g., educational, psychosocial, social support).

\section{Evaluation phases}

The PPM was used to determine the metrics to evaluate the performance of the overall RehabMaLL, and these metrics are used in the ongoing monitoring and reporting of outcomes. The evaluation of the RehabMaLL project is ongoing and results will be published subsequently.

\section{Phases 7, 8, and 9: Process, impact, and outcome evaluation}

The process evaluation includes an analysis of procedures in place for reaching the target population, and examining whether these processes are working as planned. Green and Kreuter [28] recommend evaluating whether the interventions addressed the factors identified at Phase 4 (educational and organizational assessment). For the RehabMaLL projects, an example of a metric for this phase would be reporting on the percentage of recommended interventions/solutions that were accepted by mall management. And for the interventions/solutions that were accepted, an analysis on the gaps between what was planned, and what was actually implemented will be conducted. During the process evaluation, an analysis of the key predisposing, enabling, and reinforcing factors that were targeted for change by the selected interventions are also planned.

The impact and outcome evaluations examine the immediate and long-term in-vivo effects of the interventions on physical and cognitive function, social participation, and inclusion of persons with disabilities. Sustainability of these effects will also be investigated. Green and Kreuter [28] recommend determining the impact of the interventions on addressing the issues identified in Phase 3 (in this case, inclusivity issues impacting function and participation at the mall identified by the behavioral and environmental assessments). An impact evaluation will therefore assess the immediate changes brought by the program and interventions to the target population in terms of changes in various spheres (environmental, social, educational, psychosocial etc.) and improving the degree of inclusivity. This evaluation is achieved by comparing baseline assessments of the physical and social environment to the post intervention assessments. More specifically, the impact evaluation will measure baseline and post-implementation experiences, knowledge, attitudes, and beliefs of mall patrons with disabilities

Table 3. Interventions resulting (or underway) from the RehabMaLL project.

Issue/determinant of function and participation

Poor interior signage limiting wayfinding

Limited wheelchair access from outside

Small and poorly located elevator for wheelchair access

Difficult to locate information kiosk limiting wayfinding

Lacking accessible washroom for people with mobility-related disabilities and wheelchairs

Poor knowledge of how to interact with clients living with disabilities

Poor lighting, with lots of shadow zone, impacting visibility for people with poor vision

No indicators on the floor indicating the presence of stairs or other architectural component, limiting navigation for people with low vision Floor reflection/glare impacting visibility for people with low vision
Intervention

Increased number of signs and floor identifiers at key locations to improve navigation to washrooms, elevators, and information booth; branding signage changed to be coherent across storefronts.

Addition of 2 accessible ramps for expanded wheelchair accessibility (one on each of lower and ground levels).

A new elevator, centrally located, is both accessible and large enough to accommodate more than one person in a motorized wheelchair with other people.

Information kiosk was moved to a new location in front of the new elevator and the stairs in the center of the mall. Easily seen from every floor and from everywhere on the Mezzanine level.

Addition of a new accessible "family" washroom on the street level and relocation of all washrooms on the level; changes to lower level washrooms.

Creation of a training tool kit and training of some employees of the stores/shops of the mall.

Changing of all the lighting in the ceilings at the metro and street levels. Includes change to LEDs (brighter light with less shadow) and an increased number of luminaires.

Indicators on the floor indicate the presence of stairs or other architectural elements.

New floor is "matte" not glazed. No more glare for people with low vision. 
to determine if changes occurred, and whether these changes resulted from the intervention. This will provide an indication of the immediate impacts of the program on the degree of inclusivity at the mall, both objective and subjective (i.e., a subjective or objective decrease in social obstacles that people with disabilities face at the mall). The interventions implemented to date (or underway; Table 3) are expected to improve a number of inclusivity issues, such as improved wayfinding to key areas in the mall for individuals with low vision and/or mobility impairments, improved wheelchair access to the mall, improved access to washrooms for people with mobility-related disabilities and wheelchairs, and improved social interactions between mall employees and people with disabilities.

While the impact and outcome evaluation phases can overlap, the latter focuses primarily on determining whether the program met the ultimate goal of the RehabMaLL, which is "transforming the mall into an inclusive environment welcoming all people irrespective of their physical or mental capacities". For outcome evaluation, Green and Kreuter [28] recommend determining whether the interventions and overall project led to the overall desired results identified in Phases 1 and 2. In other words, can it now be said the mall is more inclusive than before, and to what degree? To answer this, researchers and individuals with disabilities recently conducted an initial walk-through to assess the impact of the implemented changes from a user's perspective. However, given that the RehabMaLL project spans a limited number of years, measuring long-term outcomes will be challenging. The performance of any given living lab is intimately linked to the degree of its maturity.[26] The outcome evaluation of the RehabMall project will examine participation, social inclusion, and quality of life of people with disabilities, and will also investigate the sustainability of the implemented interventions. The findings from the impact and outcome evaluations of the RehabMaLL project will be disseminated in the future.

\section{Discussion}

Living lab projects can present a number of challenges due to the complexity of the dynamic lived environment, and dealing with many different stakeholder groups as well as sources of information to be considered. In this paper, we illustrated the applicability of the PPM when used as a framework for the development of an inclusive environment in an existing and renovation-ready mall setting. The PPM is primarily used in the planning and development of health promotion and educational programs.[28] However, our findings demonstrate that the PPM is flexible and accommodates a wide range of program objectives, including those targeting broader social issues relating to inclusivity of public spaces. The use of the PPM to guide the RehabMaLL project effectively facilitated the integration and synthesis of information from many different sources, as well as the identification and prioritization of key issues to address in order to improve inclusiveness at Alexis Nihon. The PPM also helped frame and drive the implementation and evaluation of the ongoing components of the projects. The need for inclusive spaces to better accommodate the elderly and people with disabilities within mall environments will only continue to grow as populations continue to age. It is hoped that the findings presented in this paper can help future development and implementation of community-led projects aiming to create enabling and inclusive public spaces such as malls.

The PPM planning phases allowed a thorough identification of the target population's need and prioritization of issues to address. Factors that were important and changeable via interventions and environmental modifications were taken into account.
Importantly, given the ecological approach of the PPM, a wide range of issues impacting the degree of inclusivity at the mall were examined and a number of inclusivity and accessibility issues related to the physical environment, policy, educational, and psychosocial aspects were identified and addressed, thus increasing the person-environment fit.[12-14] Further, the use of the PPM for the identification of predisposing, enabling, and reinforcing factors facilitated the development of mall interventions by allowing for their prioritization based on importance and changeability/ feasibility. The driving factors of reduced inclusivity at the Alexis Nihon mall were tied to limited awareness, knowledge, and access to information. Setting aside cost considerations, many issues could be resolved due to their high degree of changeability and feasibility. However, the final decisions regarding whether or not to implement an intervention were made by the mall owner. The activities resulting from the planning phases of the PPM supported this decision-making, as valuable evidence-based information and recommendations were fed back to the mall ownership/ management, shop owners, and employees.

The implementation and evaluation phases of the PPM helped translate the needs assessment and prioritization of issues/interventions conducted in earlier phases into solid commitments by the mall owner to implement interventions aimed at increasing the social participation of people with disabilities within the Alexis Nihon mall. This commitment was the result of solid relationships forged between project leaders and mall management. The implementation of activities was an iterative process and stakeholders were continuously engaged in order to provide feedback that helped increase the relevance of the interventions. The PPM also incorporates an evaluation process that allows for the monitoring of goals. Further, although the evaluation components are in the latter half of the PPM, evaluation should be taken into consideration during the planning phases of the PPM in order to develop proper evaluation metrics.

Despite the pertinence of using the PPM as a framework to develop inclusivity within public spaces, there are limitations to using a planning-focused model, particularly with respect to the evaluation of the projects and program of research. While there are established procedures to guide the synthesis and prioritization of information in the planning phases, there is less guidance available regarding the PROCEED evaluation phases, aside from the recommendation to link particular evaluative phases to specific PRECEDE phases. There are no proposed comprehensive and evidence-based approaches to evaluation. That said, the PPM should not be considered as a replacement for an exhaustive evaluation approach based on supportive research/evidence-based activities (e.g., pre- and post-intervention measurements of inclusivity, use of reliable, and valid metrics), which we recommend to be developed in parallel with the PPM. That the PPM provided less of a comprehensive approach for evaluation compared to planning, however, is a feature inherent in planning oriented frameworks.

In addition to the impacts observed on the degree of inclusivity at the mall, the interventions had broader indirect impacts on the rehabilitation field itself. Indeed, removing environmental and social barriers in public areas might promote the rehabilitation process by facilitating the restoration of function.[22] In terms of project outcomes, many rehabilitation professionals and researchers involved in the RehabMaLL project reported increased consideration of social participation and inclusivity in their research and clinical activities, leading to a reexamination of usual treatment approaches in order to better respond to the needs of their patients.[38] Many researchers and rehabilitation professionals also reported paying closer attention to these issues during their 
teaching and training of clinicians. While these outcomes have only been captured anecdotally, it may be important to consider these types of potential outcomes early in the planning process and to integrate them in the evaluation approach in addition to the more direct outcome measures associated with the mall environment and community. Finally, some of the research subprojects also contributed to the identification of potential rehabilitation interventions, through interviews with clinicians and people with disabilities. Other studies, such as those based on virtual reality, have also been completed,[47] or are underway, and could help develop novel rehabilitation interventions relevant to a mall setting. As a final caveat, it is important to underscore that such a project is suited to high resource environments and may not be feasible in resource-deprived environments, such as locations within lowand middle-income countries.[48]

In summary, this paper demonstrates the applicability of the PPM as a framework for the development of an enabling and inclusive environment in a renovation-ready shopping mall in Canada's second largest city. Since design exclusion tends to occur early in the design process, it may be worthwhile and practical to consider issues of inclusivity earlier in the design process of new shopping malls. Creating an inclusive mall environment, through decisions made early in the design process or via the renovation of existing space, will help increase the participation of patrons with disabilities. This will help reduce the marginalization of people with disabilities by increasing the visibility of disabilityadapted interventions and changing the perceptions and awareness of all mall patrons. Indeed, RehabMaLL data showed that limited awareness, education, and knowledge, appeared to be major contributing factors to numerous issues of inclusivity within the Alexis Nihon mall. These findings reflect the much broader social aspects of disability awareness at play hindering the fair and equal to services and resources within public settings. Finally, one suggestion or future direction for research, might be the development of standardized measures of inclusivity (i.e., an inclusivity index), which could be used to better quantify inclusivity at malls, and to facilitate the evaluation of the impacts of interventions and outcomes of projects targeting inclusivity.

\section{Disclosure statement}

All the authors were involved in the design, and implementation of the research. M. Milot, C. Gaudet, and S. Ahmed wrote the manuscript and all coauthors reviewed and edited the manuscript.

\section{Funding}

This work was supported by Les Fonds de Recherche du Québec Santé (FRQS) [24499]. Sara Ahmed and Anouk Lamontagne are supported by an FRQS research salary award. Joyce Fung holds a William Dawson Scholar award from McGill University. Hélène Lefebvre holds a chaire de recherche en sciences infirmières et paramédicales de l'Université de Bordeaux 2017-2019 (research chair).

\section{ORCID}

Sara Ahmed (iD http://orcid.org/0000-0001-5172-6790

Gillian Bartlett (ID http://orcid.org/0000-0001-6297-9240

Barbara Mazer (iD http://orcid.org/0000-0003-0557-2457

Guylaine Le Dorze (iD http://orcid.org/0000-0002-2760-917X

Skye Barbic (D) http://orcid.org/0000-0002-7076-2452

Ana Maria Rodriguez (iD http://orcid.org/0000-0001-6335-3223

Joyce Fung (iD http://orcid.org/0000-0002-6074-551X
Delphine Labbé (ID) http://orcid.org/0000-0002-3730-4310

\section{References}

[1] Zakus JDL, Lysack CL. Revisiting community participation. Health Policy Plan. 1998;13:1-12.

[2] Statistics Canada. Disability in Canada: initial findings from the Canadian Survey on Disability. In: Division SaAS, editor. 2013.

[3] Milner P, Kelly B. Community participation and inclusion: people with disabilities defining their place. Disabil Soc. 2009;24:47-62.

[4] Verdonschot MM, De Witte LP, Reichrath E, et al. Community participation of people with an intellectual disability: a review of empirical findings. J Intellect Disabil Res. 2009;53:303-318.

[5] Cornwell EY, Waite LJ. Social disconnectedness, perceived isolation, and health among older adults. J Health Soc Behav. 2009;50:31-48.

[6] El Hedhli K, Chebat JC, Sirgy MJ. Shopping well-being at the mall: construct, antecedents, and consequences. J Bus Res. 2013;66:856-863.

[7] Ng CF. Satisfying shoppers' psychological needs: from public market to cyber-mall. J Environ Psychol. 2003;23: 439-455.

[8] Kim YK, Kang J, Kim M. The relationships among family and social interaction, loneliness, mall shopping motivation, and mall spending of older consumers. Psychol Market. 2005;22:995-1015.

[9] Swaine B, Labbé D, Poldma T, et al. Exploring the facilitators and barriers to shopping mall use by persons with disabilities and strategies for improvements: perspectives from persons with disabilities, rehabilitation professionals and shopkeepers. ALTER-European J Disabil Res. 2014;8: 217-229.

[10] Barker RG. Habitats, environments, and human behavior: studies in ecological psychology and eco-behavioral science from the Midwest Psychological Field Station, 1947-1972. San Francisco: Jossey-Bass; 1978.

[11] Barr JJ, Bracchitta K. Attitudes toward individuals with disabilities: the effects of contact with different disability types. Current Psychologie. 2015;34:223-238.

[12] Lawton M. Environment and other determinants of wellbeing in older people. Gerontologist. 1983;23:349-357.

[13] Lawton MP, Brody EM, Turner-Massey $P$. The relationships of environmental factors to changes in well-being. Gerontologist. 1978;18:133-137.

[14] Lawton MP. The elderly in context perspectives from environmental psychology and gerontology. Environ Behav. 1985;17:501-519.

[15] Rowles GD. Growing old "inside": aging and attachment to place in an Appalachian community. In: Lohmann NDaN, editor. Transitions of aging. New York: Academic Press; 1980. p. 153-170.

[16] Rowles GD. Evolving images of place in aging and "aging in place". Generations. 1993;17:65-70.

[17] Kehayia E, Swaine B. A rehabilitation living lab: creating enabling physical and social environments to optimize social inclusion and social participation of people with disabilities. Submission to FRSQ Strategic Innovative Project (Projet strategique innovant). McGill University, Université 
de Montréal, Centre de recherche interdisciplinaire en Réadaptation (CRIR): FRSQ; 2010.

[18] Poldma T, Kehayia E, Swaine B. Building community together through collaborative research: an innovative living lab. In: Vaikla-Poldma T, editor. Meanings of Designed Spaces. New York: Fairchild Books; 2013:374-386

[19] Afacan Y. Achieving inclusion in public spaces: a shopping mall case study. In: Langdon P, PR JC, Lazar J et al., editors. Designing inclusive systems. London: Springer; 2012. p. 85-92.

[20] Poldma T, Labbé D, Bertin S, et al. Understanding people's needs in a commercial public space: about accessibility and lived experience in social settings. ALTER-European $\mathrm{J}$ Disabil Res. 2014;8:206-216.

[21] Dong H, Cassim J, Coleman R, et al. Design for inclusivity: a practical guide to accessible, innovative and user-centred design. Aldershot, Hampshire: Gower Publishing Ltd; 2012.

[22] Steinfeld ED. Theory as a basis for research on enabling environments. In: Steinfeld ED, editor. Enabling environments: measuring the impact of the environment on disability and rehabilitation. New York, NY: Kluwer Academic/ Plenum Publishers; 1999. p. 11-34.

[23] Amsel R, Fichten CS. Effects of contact on thoughts about interaction with students who have a physical disability. J Rehabil. 1988;54:61-65.

[24] Butler-Jones D. The Chief Public Health Officer's report on the state of public health in Canada, 2010: growing older-adding life to years. Ottawa: Public Health Agency of Canada. 2010.

[25] Picard R, Poilpot L. Pertinence et valeur du concept de "Laboratoire vivant» (Living Lab) en santé et autonomie. In: Le Conseil général de l'économie dli, de l'énergie et des technologies, editor. France: Ministère de L'Économie des finances et de I'Industrie; 2011;38.

[26] Dubé P, Sarrailh J, Billebaud C, et al. Qu'est-ce qu'un living lab? Le livre blanc des living labs. Montréal: Umvelt; 2013.

[27] Green L, Kreuter W. Health promotion planning: an educational and ecological approach. 3rd edition. Mountain View, CA: Mayfield Publishing Company; 1999

[28] Green LW, Kreuter MW. Health program planning: an educational and ecological approach. New York: McGraw-Hill; 2005.

[29] Porter CM. Revisiting Precede-Proceed: a leading model for ecological and ethical health promotion. Health Educ J. 2016,75:753-764

[30] Crosby R, Noar SM. What is a planning model? An introduction to PRECEDE-PROCEED. J Public Health Dent. 2011;9:271-280.

[31] Rezapour B, Mostafavi F, Khalkhali HR. School-based and PRECEDE-PROCEED-Model intervention to promote physical activity in the high school students: case study of Iran. Glob J Health Sci. 2016;8:271-280

[32] Hashimoto K, Zuniga C, Nakamura J, et al. Integrating an infectious disease program into the primary health care service: a retrospective analysis of Chagas disease communitybased surveillance in Honduras. BMC Health Serv Res. 2015;15:116.

[33] Nadrian H, Morowatisharifabad MA, Bahmanpour K. Development of a rheumatoid arthritis education program using the PRECEDE_PROCEED Model. Health Promot Perspect. 2011;1:118-129.

[34] Cornwall A, Jewkes R. What is participatory research?. Soc Sci Med. 1995;41:1667-1676.

[35] Jette AM. Toward a common language for function, disability, and health. Phys Ther. 2006;86:726-734.

[36] World Health Organization. International Classification of Functioning, Disability and Health: ICF. Geneva, Switzerland: World Health Organization; 2001.

[37] Grasso F, Desjardins M, Labbé D, et al. Opérationnaliser l'inclusion dans les projets innovants. L'expérience du "MALL» à l'aune de la classification internationale du fonctionnement. ALTER-European J Disabil Res. 2014;8: 158-169.

[38] Kehayia E, Swaine B, Longo C, et al. Creating a rehabilitation living lab to optimize participation and inclusion for persons with physical disabilities. ALTER-European J Disabil Res. 2014;8:151-157.

[39] Mazurik K, Desjardins M, de Grosbois $\grave{E}$, et al. Individual stakes and collective ideology in tension: looking at physical and spatial obstacles from an experiential perspective. ALTER-European J Disabil Res. 2014;8:194-205.

[40] Lefebvre H, Levert M-J. Supporting people with traumatic brain injury in their use of public spaces: identifying facilitating factors and obstacles. ALTER-European J Disabil Res. 2014;8:183-193.

[41] Desjardins M, Ville I, Mazurik K. De quelques constructions théoriques et méthodologiques des obstacles à la participation sociale, le cas du projet CRIR-Living lab vivant. ALTEREuropean J Disabil Res. 2014;8:141-145.

[42] Torkia C, Reid D, Korner-Bitensky N, et al. Power wheelchair driving challenges in the community: a users' perspective. Disabil Rehabil: Assist Technol. 2015;10:211-215.

[43] Rushton PW, Kairy D, Archambault P, et al. The potential impact of intelligent power wheelchair use on social participation: perspectives of users, caregivers and clinicians. Disabil Rehabil: Assist Technol. 2015;10:191-197.

[44] Kairy D, Rushton PW, Archambault P, et al. Exploring powered wheelchair users and their caregivers' perspectives on potential intelligent power wheelchair use: a qualitative study. Int J Environ Res Public Health. 2014;11:2244-2261.

[45] Bottari C, Shun PLW, Le Dorze G, et al. Self-generated strategic behavior in an ecological shopping task. Am J Occup Ther. 2014;68:67-76.

[46] Auger C, Leduc E, Labbé D, et al. Mobile applications for participation at the shopping mall: content analysis and usability for persons with physical disabilities and communication or cognitive limitations. Int J Environ Res Public Health. 2014;11:12777-12794.

[47] Lamontagne AKE, Bugnariu N, Fung J. Virtual reality reveals mechanisms of balance and locomotor impairments. In: Weiss PL (Tamar) KE LM, editor. Virtual Reality Technologies for Physical and Motor Rehabilitation. New York, NY: Springer; 2014. p. 169-202.

[48] Babulal GM, Bahkshi P, Kopriva S, et al. Measuring participation for persons with mental illness: a systematic review assessing relevance of existing scales for low- and middleincome countries. BMC Psychol. 2015;3:36. 